\title{
LA SERIE SOBRE SAN FERNANDO DE ANTONIO GARCÍA REINOSO EN LA CATEDRAL DE CÓRDOBA
}

\author{
POR \\ José María Palencia Cerezo \\ Museo de Bellas Artes de Córdoba
}

\begin{abstract}
La reciente restauración de los lienzos pintados por García Reinoso para conmemorar la canonización de Fernando III el Santo en la Catedral de Córdoba, no sólo ha servido para poder admirar las obras en sus calidades originarias, sino que también han aportado datos imprescindibles para fijar su exacta cronología; trayendo a primer plano de la actualidad la pintura de este artista, mayormente conocido por sus cualidades como dibujante, conociéndose suyas muy pocas obras pictóricas, en particular de su momento de madurez. En este artículo se aborda el estudio iconográfico de la serie, procediéndose a la interpretación de unos temas que hasta el momento habían sido tratados bastante desigualmente.
\end{abstract}

Palabras clave: García Reinoso; San Fernando; Catedral de Córdoba; Pintura; Siglo XVI.

The recent restoration of canvases painted by García Reinoso to commemorate the canonization of Ferdinand III, the Saint, in Córdoba Cathedral allows not only for the appreciation of the original quality of these works, but also contributes invaluable data for determining their exact chronology. The painted production of this artist, known primarily for his abilities as a draughtsman, is thereby brought into focus, given that very few of his paintings are known, particularly from his mature period. This article offers an iconographical study of the series and interprets certain themes that until now have not been fully addressed in the scholarly literature.

Key words: García Reinoso; Saint Ferdinand; Córdoba Cathedral; Painting; $16^{\text {th }}$ Century.

Como es conocido, la canonización del rey Fernando III en 1671 gnificó uno de los acontecimientos más relevantes de la Iglesia española en el siglo XVII, estrechando todavía más ese indisoluble nexo sellado desde mucho tiempo atrás, entre Monarquía e Iglesia. Con motivo de la misma y como era habitual en estos casos, en todas las ciudades se llevaron a cabo festivas celebraciones, que en Andalucía y especialmente en Sevilla, revistieron una especial singularidad, convirtiéndose en una de las más importantes de España, pues Fernando III no sólo había conquistado esta ciudad a los árabes, sino que, además, había fallecido cuando se encontraba 
planeando desde allí, el paso definitivo del Estrecho de Gibraltar en su cruzada contra los infieles, siendo allí enterrado ${ }^{1}$.

Respecto al caso de Córdoba, mucho antes de su definitiva elevación a los altares, la ciudad había venido demostrando una especial predilección hacia este guerrero modelo de virtud, habiendo recibido culto en ella mucho antes de su canonización, no sólo en su persona, sino particularmente a través de la imagen de Nuestra Señora de Linares, que según la tradición había sido traída por él a la ciudad cuando su asedio, y a la que había dado santuario en una torre atalaya próxima al lugar en que se sus tropas acamparon para dar el golpe definitivo ${ }^{2}$.

Como fue también habitual para este tipo de acontecimientos, la celebración por la canonización de San Fernando tuvo en Córdoba una doble vertiente: la popular-folclórica y la religiosa. La popular, y según acuerdo del Concejo de 19 de abril, consistió en la celebración de fiestas de toros en la Plaza de la Corredera. Sin embargo, no se tiene una idea exacta de cómo se llevaron a cabo las festividades religiosas celebradas en la Catedral con todo el boato por no haberse impreso ningún libro que describiese el acontecimiento, no teniéndose datos suficientes para poder reconstruir el posible monumento efímero que, según Moreno Cuadro, debió haber sido erigido en la Capilla de Villaviciosa ${ }^{3}$, presidiendo los actos que se desarrollaron a lo largo de tres días seguidos, una semana después de lo preceptivo, y que lo más importante que dejaron para el futuro, fue un altar dedicado al nuevo Santo. Era entonces obispo de Córdoba don Francisco de Alarcón y Covarrubias (Valladolid, 1589-Córdoba, 1675), gran mecenas de las artes, que ocupó la silla de Osio entre 1658 y $1675^{4}$.

En todo caso, dado que entonces no había sido realizada todavía la serie conmemorativa que sería ejecutada por el pintor Antonio García Reinoso, es lógico suponer que la celebración se hiciese teniendo una imagen presente, la cual, a nuestro juicio no debió ser otra que la que en la actualidad se conserva en su altar de la Capilla Real, por más que diversos historiadores actuales la consideren anónima del siglo XVIII 5 .

Pero al margen del misterio sobre la talla de 1671 y su posible autoría, sabemos que la canonización fue perpetuada por el cabildo catedralicio mediante el encargo de un conjunto de cuatro lienzos a García Reinoso, que habrían de ir situados en los ventanales ciegos del piso superior del presbiterio de la catedral nueva. Sin embargo, lo que no ha sido conocido hasta el presente

${ }^{1}$ El magnífico aparato efímero levantado en su Catedral con tal motivo, reflejado en el libro de Fernando de la Torre Farfán, Fiesta de la Santa Iglesia de Sevilla Al Culto, nuevamente concedido Al Señor Rey San Fernando III de Castilla y León, ha sido estudiado en nuestros días por Moreno Cuadro, interpretando sus jeroglíficos. Véase MorENO CuAdro, Fernando: "Humanismo y Arte Efímero Hispalense: la Canonización de San Fernando", Traza y Baza, Departamento de Arte de la Universidad de Valencia, 9, 1985, pp. 21-98.

2 Véase Redel, Enrique: La Virgen de Linares conquistadora de Córdoba. Memorias históricas acerca de esta antigua imagen y de su santuario, culto y hermandad (1236-1907), Córdoba, 1910.

${ }^{3}$ Moreno Cuadro, F.: Las celebraciones públicas cordobesas y sus decoraciones, Córdoba, 1988, p. 47. Gómez Bravo, a quien por lógica histórica debía corresponder también la narración de lo ocurrido, sólo escribió sobre el particular que “... el Pontifice Clemente X, declaró a siete de Febrero de mil seiscientos setenta y uno la Santidad, y culto inmemorial de San Fernando Rey de Castilla y León, con facultad de poder celebrarle a treinta de Mayo (en que murió) en todos los Dominios de Rey Católico con Rito doble en Misa, y Oficio Divino. Esta noticia muy deseada en todo el Reyno, le llenó de summa alegría, y en Córdoba, que ya a seis de marzo había llegado, se celebró con públicos regocijos. En la Catedral se celebraron tres días con todas las demostraciones festivas, y empezaron Domingo siete de Junio, por venir el día propio en infraoctava del Corpus... En la Capilla de Villa-Viciosa se erigió altar al Santo, y en adelante se ha celebrado su día con repiques, y solemnidad de primera clase, y observado por fiesta de precepto, conforme al Breve de veinte y seis de Agosto de setenta y tres". Gómez BRAVO, Juan: Catálogo de los Obispos de Córdoba, 1778, tomo II, pp. 704-705.

4 Véase Nieto Cumplido, Manuel: La Catedral de Córdoba, 1998, p. 454.

${ }^{5}$ Nieto Cumplido, 1998, p. 463. Ni Nieto ni Moreno estudian esta imagen en sus significativos trabajos de conjunto. Véase también Moreno CuAdro, F.: Iconografia de San Fernando en Córdoba, 1989. 
es que no le fueron encargados - $\mathrm{O}$ al menos no fueron comenzados por éste- hasta cuatro años después de la celebración del fasto, aunque no resulten del todo claras las circunstancias que rodearon encargo y realización.

Ello ha sido posible gracias a la reciente restauración de que han sido objeto a cargo de Miguel Vázquez Arjona ${ }^{6}$, que ha aportado los datos necesarios para poder resolver algún misterio, ya que, en uno de ellos ha aparecido escrito por mano del artista, que le fueron encargados el 6 de agosto de 1675, siendo finalizados un año después, el 29 de agosto de 1676 (figs. 1 y 2).

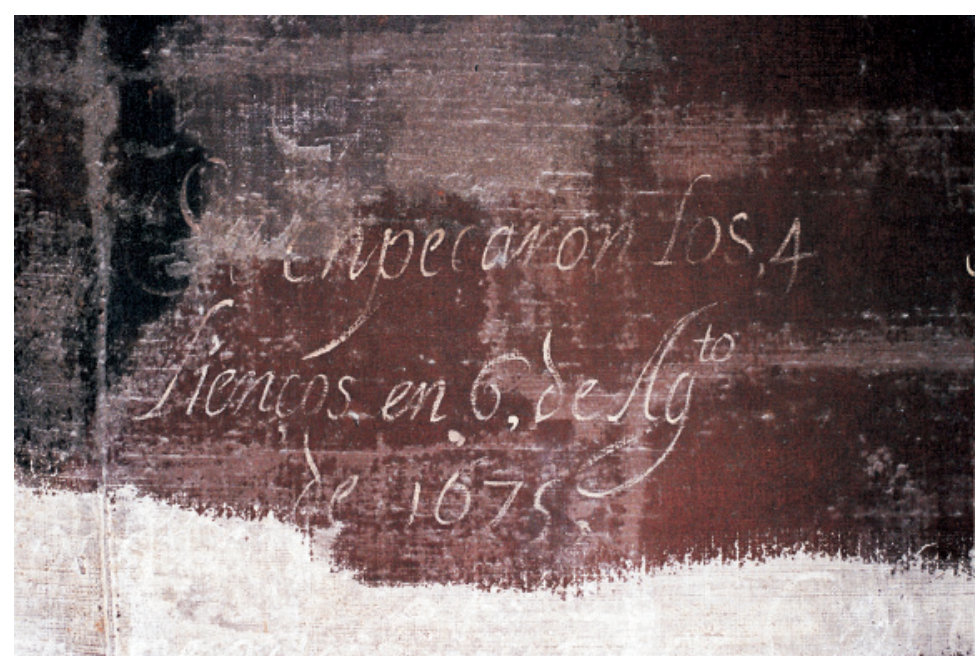

Fig. 1. Antonio García Reinoso. San Fernando en la conquista de Sevilla. Inscripción al dorso relativa al comienzo de la serie.

Según ello, el comienzo del trabajo se produjo justo tras el fallecimiento del obispo Alarcón y Covarrubias, que sucedió el 18 de mayo de 1675, mientras la entrega se efectuó recién estrenado cargo por su sucesor, el franciscano fray Alonso de Salizanes, que tomó posesión del obispado el 28 de enero de 1676, aunque no entra en la ciudad hasta el 28 de marzo, residiendo ya en ella hasta finalizar sus días en 1685 .

De ello podemos deducir o establecer varias hipótesis. La primera sería que el encargo fue realizado una vez producido el óbito de Alarcón y Covarrubias, aun con conocimiento de éste, que es probable que desde 1671 se encontrase ansioso por tener la serie colgada en el nuevo y majestuoso presbiterio, cuya arquitectura llevaba ya tiempo finalizada. No obstante, es posible también que fuera el Cabildo el que mediara en el encargo, pretendiendo su realización en un corto espacio de tiempo y antes de la entrada del nuevo mandatario de la Diócesis. Por otro lado, dado que no han aparecido hasta el momento documentos al respecto, puede que el encargo mediara sin pactar contrato alguno, lo que habría dado motivo a que el artista escribiera al dorso

\footnotetext{
${ }^{6}$ Agradezco a Miguel Vázquez la gentileza que ha tenido proporcionándome los datos e imágenes finales de su trabajo, que llevó a cabo entre 2003 y 2005, es decir más de doscientos veinticinco años después de que, en 1774, hubieran de ser bajadas de su emplazamiento para ser "retocadas" en tiempos del obispo Francisco Garrido de la Vega, por mediación del canónico obrero Cayetano Carrascal, como también se ha sabido por su restauración.
} 


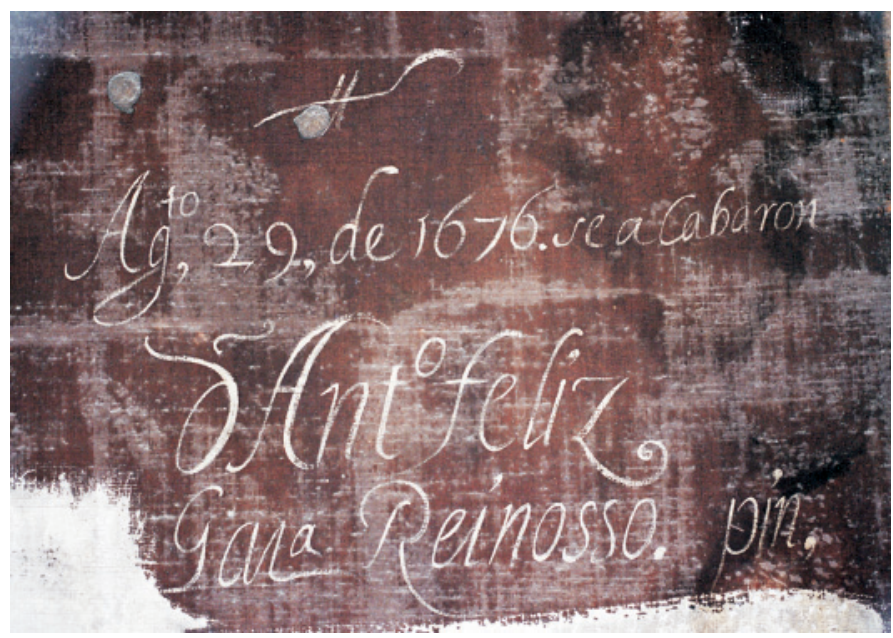

Fig. 2. Antonio García Reinoso. San Fernando en la conquista de Sevilla. Inscripción al dorso relativa al fin de la misma y firma del artista.

sus circunstancias de compromiso y acabado, las cuales permiten fijar la cronología exacta de la serie sin tener que acudir a documento alguno.

Por lo demás, cabe decir que los actuales estudios sobre Reinoso han puesto de manifiesto, al contrario de lo aportado por Palomino, que había nacido en Granada y no en Cabra (Córdoba); aunque, partiendo de su afirmación de que había fallecido en Córdoba en 1677, a los cincuenta y cuatro años de su edad, muchos autores siguen creyendo que nació en 1623, y aunque no se ha encontrado todavía su partida de nacimiento, es probable que lo hubiera hecho algunos años antes, hacia $1620^{7}$.

En todo caso, al menos en este primer momento, Granada no debió de influirle mucho, pues con siete años se le documenta avecindado en Cabra con sus padres. Se ignora también quién fuera realmente su maestro, a pesar de que Valverde lo hace llegado a Córdoba desde Jaén, donde habría estado mucho tiempo al lado de Sebastián Martínez Domedel (c. 1616-1667), cuya trayectoria tampoco es suficientemente conocida. Es posible que, antes de establecerse definitivamente en Córdoba, y como dice Ceán, hubiese pasado por Granada, Jaén, Andújar y Martos, aunque Augusto Mayer lo puntualizó afirmando que pasó unos años en Andujar y diez en Granada, lo que, de ser cierto, debió suceder entre 1635 y 1650, siendo en este momento cuando afianzara su arte a la sombra de alguno de sus destacados maestros del momento, que podrían haber sido Miguel Jerónimo de Cieza (1611-1685) o Ambrosio Martínez de Bustos (1614-1672), a cuyo arte también se muestra cercano.

En todo caso, el 2 de marzo de 1646 contraía matrimonio en Cabra con doña Isabel Ramírez Lorite, de familia privilegiada al parecer oriunda de Baeza, teniendo en 1647 su primer hijo, Juan Guillermo, y en 1648 el segundo, Anastasio Antonio, que debió morir pronto, pues no es citado en el testamento que se redactara poco antes de su fallecimiento. Entre 1650 y 1670 transcurren

\footnotetext{
7 Siguiendo a Palomino, Ceán Bermúdez, Sánchez Cantón, Mayer, Ramírez de Arellano, Valverde Madrid y otros, lo han venido considerando natural de Cabra. Sin embargo, en 1977 Pilar Manteca demostró su nacimiento granadino. Véase Manteca Cano, Pilar: El pintor andaluz Antonio García Reinoso, 1977, Memoria de licenciatura, Facultad de Filosofía y Letras, Universidad Autónoma de Madrid (Inédita).

8 Valverde Madrid, José: "El pintor García Reinoso", en Boletín de la Real Academia de Córdoba, 97, 1977, p. 115.
} 
otras dos décadas en que se desconoce su exacto paradero, aunque es posible que se mantuviera entre Granada, Cabra, Andújar, Martos y otros pueblos cordobeses, como Baena y Bujalance, donde también se tienen lejanas referencias suyas.

Por lo demás, parece estar claro que en 1672 se encontraba avecindado en Córdoba, donde ya en 1675 alquilaba unas casas en la calle de los Mercaderes (collación de Santiago), año en que nace su nieto Amador Silverio, fruto del matrimonio de su hijo Juan con Ana Torres. Debió regentar aquí un importante taller donde haría todo tipo de trabajos ayudado por su hijo Juan Guillermo, como consta en el documento en que afirma haberse hecho cargo del dorado de las andas del Nazareno de Doña Mencía. Fue en este taller donde debieron pintarse los cuatro lienzos para la Catedral y donde fue conocido por Antonio Palomino, que por entonces comenzaba su dedicación a la pintura tras ordenarse de menores en el Convento de Carmelitas Calzados, antes de pasar definitivamente a Madrid en $1678^{9}$.

No obstante, y al contrario que su producción dibujística que es bastante prolífica, apenas se conocen pinturas que se le puedan adjudicar con seguridad, por lo que la serie de San Fernando para Córdoba tiene una especial significación, por aparecer firmada y corresponder a su momento de madurez. Partiendo de ella podemos deducir además que su nombre de pila debió ser un compuesto de "Antonio" y "Félix", ya que es de esta manera como la rubrica, utilizando su segundo apellido -"Reinosso"- con una o dos eses según conveniencia, como se puede deducir de la comparación de la misma en la serie con la que aparece en varios de sus dibujos. Y que cuando firma en monograma con las iniciales "AG" entrelazadas, tiende a confundirse con el "AC" monogramizado de Antonio del Castillo, de ahí la confusión que ha venido reinando en la atribución de dibujos a uno u otro artista, a lo que se uniría la evidencia de la "mimetización" del arte del maestro cordobés por parte de Reinoso, especialmente desde su establecimiento definitivo en la ciudad (fig. 3).

Por último, la serie también ayuda a conocer el estilo último del artista, en este caso un tanto equívocamente, dado que las pinturas fueron hechas para ser vistas a gran altura, con figuras colosales y hasta cierto punto "desproporcionadas". Pero volviendo a la misma hay que señalar que, en nuestros días, ha sido referida por diversos autores, que la han abordado, bien desde la perspectiva de su autor, bien en relación a la Catedral de Córdoba en su conjunto; o bien en función de la iconografía del Santo. Pero hasta el momento creemos que ninguno ha sabido establecer su significación al completo, errando en alguna u otra cuestión.

Por orden cronológico lo habrían hecho Orti Belmonte en 1970, Manteca Cano en 1977, Raya Raya en 1988, Moreno Cuadro en 1989 y 2007 y Nieto Cumplido en 1998. De atrás hacia delante, Nieto fue el que menos espacio le ha dedicado en su monumental trabajo sobre la Catedral de Córdoba, errando por ejemplo al afirmar que las cuatro obras, de las que no cita temática, están firmadas ${ }^{10}$, cuando en realidad lo están la primera y la última. Raya Raya subsanó por primera vez el error de Palomino, que había hablado sólo "de dos obras con destino al presbiterio de la Capilla Mayor". Señaló su factura en 1675, pero al que alude a la conquista de Baeza lo denominó como San Fernando ofrece los reinos conquistados, al que lo hace a la toma de Córdoba como Aparición de San Pedro y San Pablo a San Fernando, mientras titula el relativo a la conquista de Sevilla como Sueño de San Fernando ${ }^{11}$.

\footnotetext{
9 Reinoso llegó a Córdoba en una coyuntura muy favorable, pues la desaparición de Cristóbal Vela, José de Saravia y Antonio del Castillo, las frecuentes ausencias de Juan de Alfaro y la minoría de edad de Palomino, le granjeó un puesto de primer orden, dedicándose por ello también al diseño de retablos y piezas de platería, siendo experto tasador de obras de arte.

${ }^{10}$ Nieto Cumplido, M., 1998, p. 539.

11 RaYa RaYA, María Ángeles: Catálogo de las pinturas de la Catedral de Córdoba, 1988, pp. 79-80.
} 


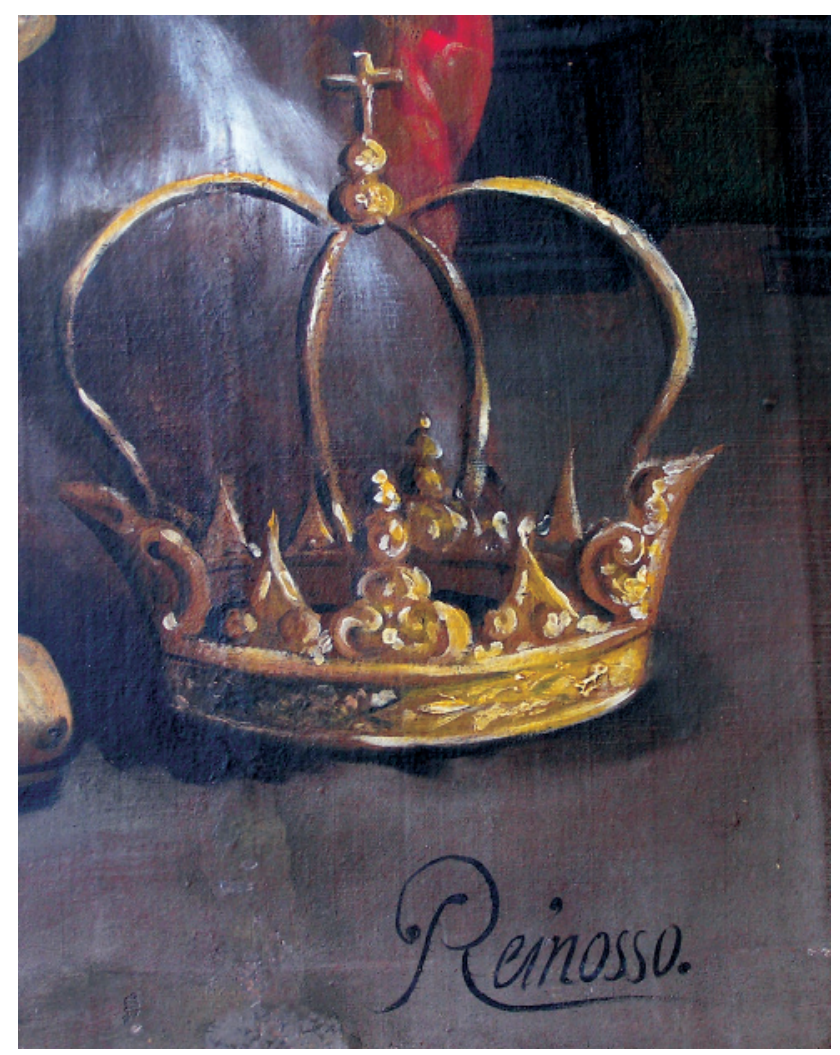

Fig. 3. Antonio García Reinoso. San Fernando en la conquista de Baeza. Detalle de la firma.

Más notorios resultan los trabajos de conjunto de Moreno Cuadro, que aunque sigue los títulos otorgados por Raya, acertará en la iconografía respecto a la obra relativa a Sevilla ${ }^{12}$; y de Manteca Cano, única en señalar que el primer cuadro representa el milagro de la parada del sol para que a las tropas les diese tiempo suficiente para ganar la batalla, aunque el suceso lo refiere a Córdoba y no a Baeza ${ }^{13}$. Por lo demás, Orti Belmonte fue muy parco en su apreciación, limitándose a afirmar que eran relativos a la vida del Santo Rey ${ }^{14}$.

En todo caso, parece claro que las cuatro obras -que miden $295 \times 145 \mathrm{~cm}$.- fueron en origen realizadas con la intención de ocupar los dos lados ciegos superiores del presbiterio. Por el lado del Evangelio quedaron finalmente situadas las conquistas de Baeza y Córdoba, mientras que por el de la Epístola, la de Sevilla y San Fernando como Monarca Universal. Ni que decir tiene que fueron hechas ex profeso, y su colocación explica la lógica de las firmas - una por cada par de obras-, y el hecho de que, en todos los casos, el protagonista dirija su mirada hacia el retablo

12 Véase Moreno Cuadro, F., 1989, pp. 36, 40, 41, 67 y 81. Y Moreno Cuadro, Fernando: "El crucero de la Catedral de Córdoba. Estudio iconográfico e iconológico", Cuadernos de Arte e Iconografía, FUE, Madrid, t. XVI, Primer semestre de 2007, pp. 234-235, donde continúa manteniendo los mismos títulos que en su trabajo de 1989.

13 Manteca Cano, P., 1977, s/p.

14 Ortí Belmonte, Miguel Ángel: La Catedral, antigua Mezquita y Santuarios cordobeses, 1970, p. 50. 
mayor de la Catedral, planteando así una lectura comprensiva que el espectador realizaría desde la parte exterior del presbiterio hacia la de dentro del mismo para salir por la zona opuesta.

En todo caso, lo que nuestra aportación tiene de novedad respecto a lo iconográfico, a diferencia de los autores aludidos, es que ninguno ha llegado a proponer que, en realidad, el conjunto simboliza la unión de las tres Iglesias o Diócesis que quedaron constituidas tras las conquistas de Fernando III en la Andalucía del siglo XIII: la de Baeza-Jaén, la de Córdoba y la de Sevilla. El resto del territorio permanecía todavía en poder de los musulmanes, formando en buena parte el llamado Reino de Granada.

Entrando en cada una de ellas con más detalle, podrían describirse como sigue:

1. San Fernando en la conquista de Baeza (fig. 4). Esta obra aparece firmada en su ángulo inferior derecho como "Reinosso", y en ella el Santo aparece semiarrodillado orando en sus habitaciones y mirando hacia el globo solar, ya que según la tradición, la toma de la ciudad por las tropas del Maestre de Calatrava fue posible gracias a sus oraciones, que produjeron el milagro de la prolongación de la luz del día, pues que la batalla se pudo haber visto perdida con la llegada de la noche. A sus pies, en el suelo, queda situada una corona de abolengo imperial.

Fernando viste rico traje de raso azul claro con aberturas en mangas y pantalón rematado en golillas, más botas doradas y capa roja con muceta de armiño, lo que pone de manifiesto su no entrada directa en la batalla. Por la parte superior derecha de la escena se abre una ventana al paisaje que deja ver el ataque de las tropas comandadas por el jefe de la Orden de Calatrava, cuya blanca bandera con la cruz de San Andrés se hace suficientemente perceptible.

Como es conocido, durante la dominación árabe, Baeza fue una importante ciudad musulmana que quedó en parte doblegada en 1212 tras la batalla de las Navas de Tolosa, erigiéndose en capital de un efímero reino taifa almohade que comprendía un amplio territorio de Jaén y Córdoba. Su emir -Allâh-al-Bayyâsi- fue vasallo de Fernando III, llegando a apoyarle en campañas contra otros emires árabes, pero murió asesinado a traición en Almodóvar del Río, por lo que el 30 de noviembre de 1227 Fernando III la conquistaba tras ser tomada por el ejercito del Maestre, concediéndole el progresista Fuero de Cuenca, que promovía la repoblación cristiana de su territorio con gentes venidas de esa ciudad. Tras su conquista y a partir de 1229, Baeza se convirtió en la primera diócesis católica de la nueva Andalucía cristiana ${ }^{15}$.

En este caso, la realidad histórica se unió a los retratos hagiográficos populares con la habitual conjunción entre realidad y leyenda, como puede verse por ejemplo en el caso del Padre Croisset, quien escribió lo siguiente al respecto: "No fue menos milagrosa la (conquista) que hizo el maestre de Calatrava del alcázar de Baeza, adonde volvió con los suyos después de haberle desamparado de noche, llamado de una resplandeciente cruz que se dejó ver sobre el castillo; y no sólo se defendió valerosamente de una multitud de moros que le sitiaban, sino que haciendo una vigorosa salida, los desalojó de la ciudad, y se hizo dueño de ella. Cercado el gran Maestre de Santiago de una innumerable muchedumbre de infieles, y estando muy dudosa la victoria, se declaró en fin por los cristianos, asegurando graves autores que detuvo el sol su carrera a la voz del gran maestre, como a la voz de Josué, por la oración de nuestro Santo, que a la sazón la estaba haciendo muy fervorosa, fijos inmoblemente los ojos hacia el Occidente"16.

2. San Fernando en la conquista de Córdoba (fig. 5). Por su relación con la ciudad ha sido el lienzo más tratado por los diversos autores locales, que lo han venido titulado como Aparición

\footnotetext{
15 Véase sobre este aspecto, Nieto Cumplido, M.: Historia de las Diócesis Españolas. Córdoba-Jaén. MadridCórdoba. 2003, pp. 68-69.

16 Croisset, J. SJ: Año Cristiano, o ejercicios devotos para todos los días del año. Traducido al castellano por el P. José Francisco de Isla. mayo, 1853, p.564. Nótese la errata del jesuita, o de la imprenta, confundiendo al Maestre de Calatrava con el de Santiago.
} 
de San Pedro y San Pablo a San Fernando ante la conquista de Córdoba, lo que tiene su lógica teniendo en cuenta el conocido relato histórico en relación con esta conquista, que se produjo el 29 de junio de 1236, día que la Iglesia conmemora la onomástica de ambos apóstoles, razón por la cual los conventos otorgados a dominicos y franciscanos fueron puesto bajo sus respectivas advocaciones.

No obstante, más allá de la piedad que los distintos tratadistas históricos le suponen al Santo, no hemos encontrado episodios concretos de intercesión divina en la conquista de Córdoba, al

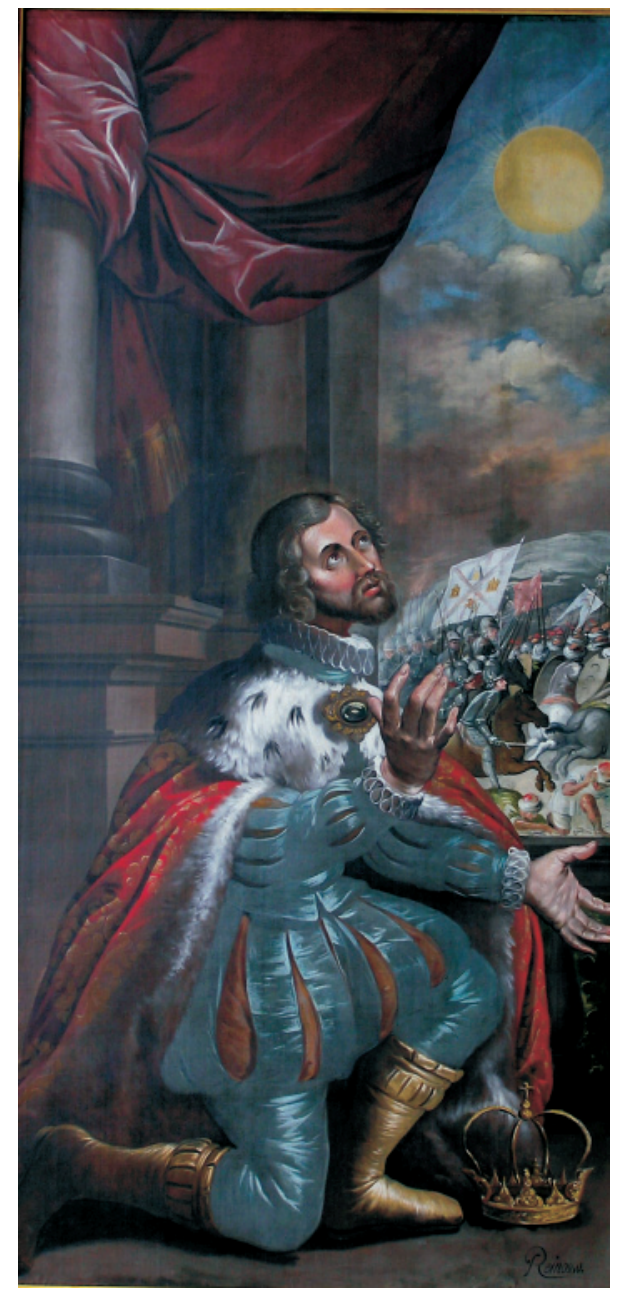

Fig. 4. Antonio García Reinoso.

San Fernando en la conquista de Baeza.

Presbiterio de la Catedral de Córdoba.

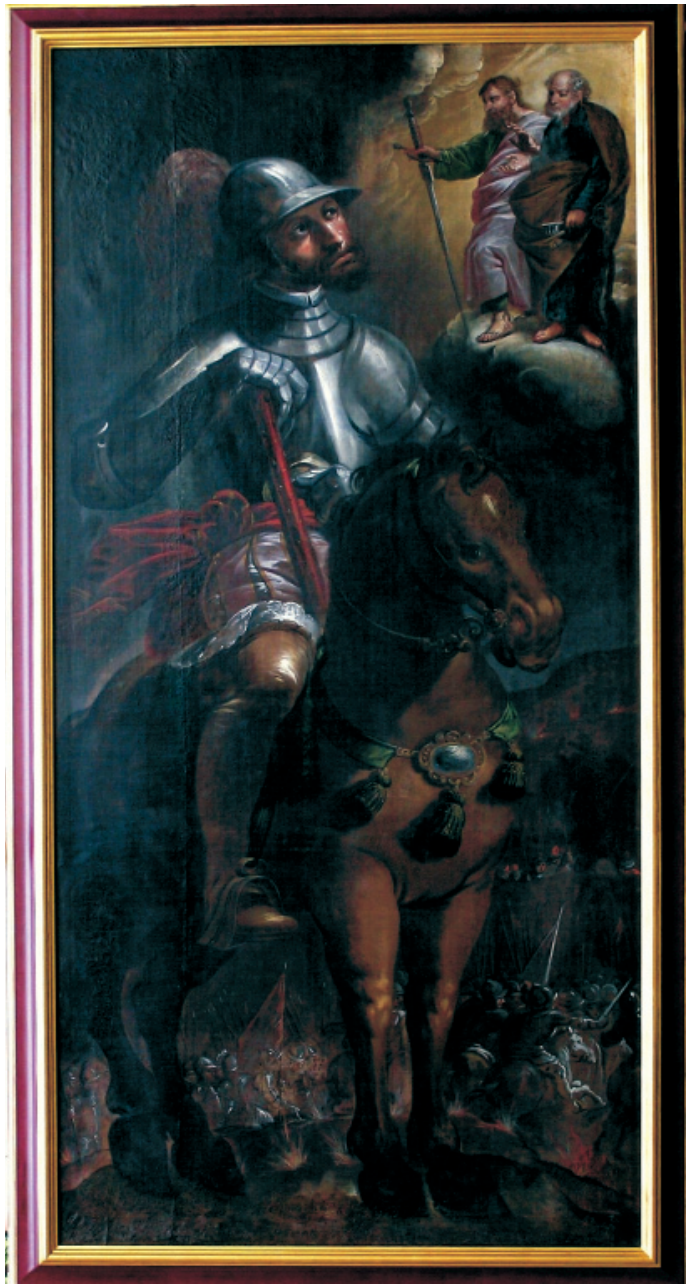

Fig. 5. Antonio García Reinoso.

San Fernando en la conquista de Córdoba. Presbiterio de la Catedral de Córdoba.

menos tan claros como con respecto a Sevilla, en relación a la cual, desde la Crónica de San Fernando hasta compilaciones biográficas modernas, como la del anónimo jesuita que en 1943 escribió su hagiografía para la colección de Vidas Populares de la editorial Apostado de la Prensa, 
aluden a que el Monarca recibió un aviso del cielo por conducto de San Isidoro, asegurándole que se apoderaría de la ciudad.

En cualquier caso, para la Catedral de Córdoba, Reinoso representó a Fernando III subido en recio corcel situado en su cara frontera y en ligera diagonal, tocado en la cintura con armadura y portando cetro y banda roja de capitán general, mientras dirige la mirada hacia el cielo, donde se le aparecen los dos apóstoles de cuerpo entero y de pie sobre una nube. A sus pies, un grueso ejército parece dispuesto a atacar la ciudad, lo que no deja de ser otra incongruencia histórica, al menos en relación a cómo en un primer momento, la ciudad fue rendida después de que el adalid Domingo Muñoz, Alvar Pérez de Castro y otros caballeros hubiesen asaltado sus murallas.

3. San Fernando en la conquista de Sevilla (fig. 6). Es el lienzo más importante de la serie, no sólo por su iconografía, sino por presentar al dorso las inscripciones que no han sido dadas a conocer hasta el presente. Dicen las mismas: "enpeçaron los 4 / lienços en 6 de Agto / de 1675". Y también "Agto., 29, de 1676. se acabaron / Sr Anto feliz / Gar ${ }^{a}$ Reinoso. pin." Además, "Se rretocaron / año de 1774 siendo Obispo de Cordoba / el Yl ${ }^{\text {tmo }}$ S. D. Francisco Garr (ido) de la ( ${ }^{\text {Vega }}$ ),/ y obrero de la Sta Yglesia (Catedral) D. Cayetano Carrascal tesorero desta Sta Yglesia."

Por ellas conocemos no sólo su ejecución, que ocupó a Reinoso todo un año entre los veranos de 1675 y 1676, sino la primera restauración de que fueron objeto, aunque desconozcamos el nombre de su autor, posiblemente el pintor cordobés Antonio Álvarez Torrado (h. 1734-1806), que trabajó mucho para la Catedral, donde restauraría también los lienzos de Palomino del retablo mayor por ser el pintor-restaurador con más prestigio del momento, ya que se había formado en la Real Academia de San Fernando.

Su iconografía podría resumirse en el título Aparición de la Virgen a San Fernando en sueños antes de la conquista de Sevilla, con el que también ha sido referido. Presenta al Monarca en melancólica disposición de ensueño delante de su lujosa tienda de campaña y sentado en un sillón frailero, mientras tres angelitos descienden para ponerle otras tantas coronas reales, sin duda alusivas a que, con esta nueva conquista, se daba paso a la unión de otras tantas diócesis andaluzas: Baeza, Córdoba y Sevilla. El color rojo de la gran tienda real, a manera de cortinaje, contrasta con los colores plata y oro de la armadura y las botas, entre las cuales aparece su espada enfundada en verde claro.

Por la parte superior izquierda se abre el paisaje en lontananza, adivinándose la silueta de un templo, que debe ser la Catedral hispalense con su popular Giralda, sobre la cual se yergue la imagen de la Virgen de los Reyes. Se trata por tanto de una representación del pasaje de la conquista de la capital de Andalucía, a la que el Padre Croisset se refirió con las siguientes palabras: "Estaba una noche el religioso Monarca haciendo oración en un templo de sus reales, delante de la imagen de Nuestra Señora de los Reyes, y oyó una voz, pronunciada por el mismo simulacro, que le decía: En mi imagen de la Antigua, de quien tanto fía tu devoción, tienes continua intercesora; prosigue, que tú vencerás" "17.

4. San Fernando como Monarca Universal (fig. 7). Se trata del lienzo que cierra la serie, haciendo pareja con el anterior por el lado de la Epístola del presbiterio, debido a lo cual aparece firmado en su ángulo inferior izquierdo como "Reinosso", nuevamente con el segundo apellido del artista.

En él representó al Monarca de pie y de cuerpo entero, vistiendo armadura de gala plata y oro jalonada en la parte baja de damasco verde, mientras cubre su cuerpo con capa real de muceta de armiño y flores de lis, la cual cierra con artístico broche de oro y plata, bajo el que cuelga un medallón con la efigie de la Virgen de los Reyes, mostrando así sus dotes para con los diseños de

\footnotetext{
${ }^{17}$ Croisset, J., 1853, p. 565.
} 


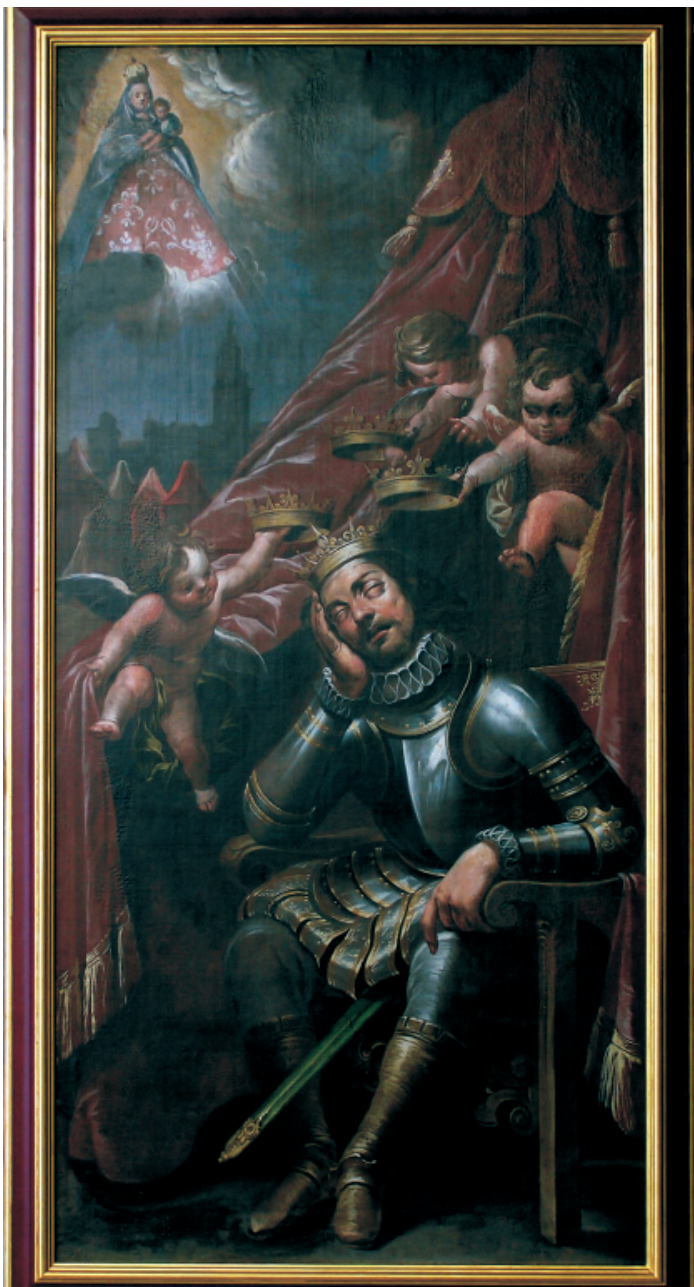

Fig. 6. Antonio García Reinoso.

San Fernando en la conquista de Sevilla.

Presbiterio de la Catedral de Córdoba.

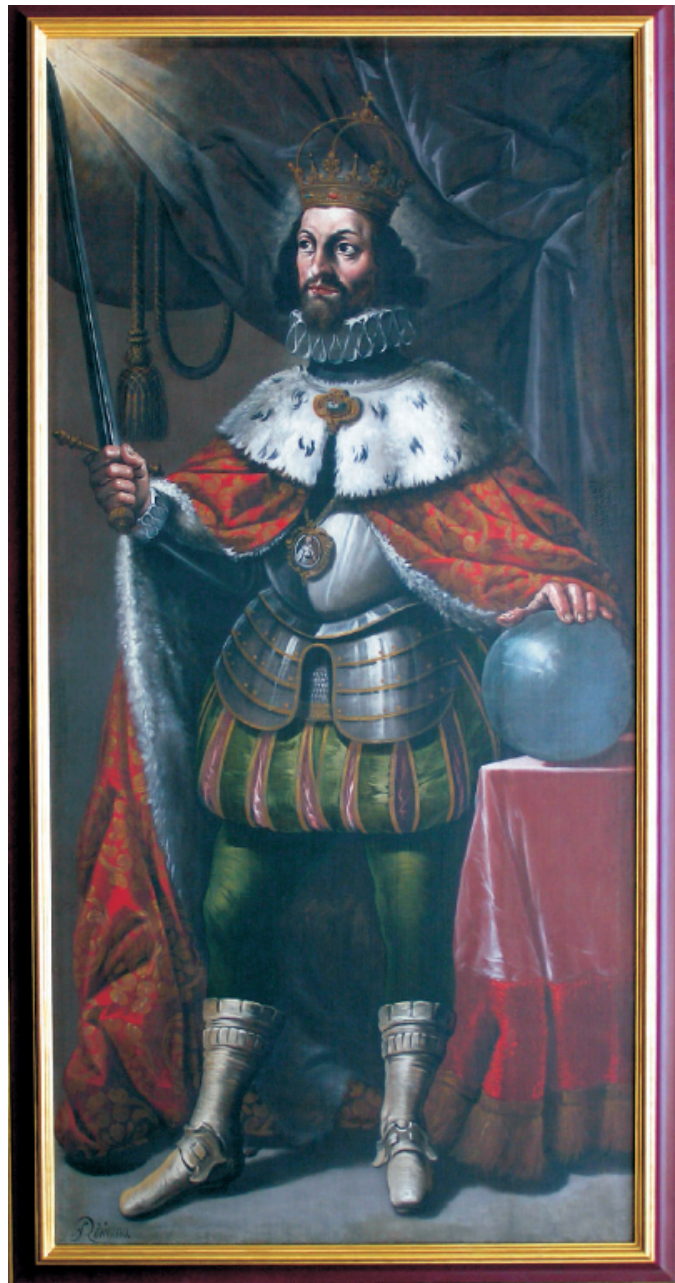

Fig. 7. Antonio García Reinoso.

San Fernando como Monarca Universal.

Presbiterio de la Catedral de Córdoba.

platería. De no ser por ello, el icono podría confundirse con la habitual de su primo San Luis IX de Francia, con quien se le suele parangonar.

Sobre la cabeza luce corona real y nimbo de santidad, mientras dispone la pose apoyando la mano izquierda sobre una bola o globo terráqueo, blandiendo con la derecha una espada en alto en señal de firmeza. Por lo demás, un grisáceo cortinaje amarrado en borlado cordón, contrasta con la mantelería de la mesa, de enagua adamascada y tapete o mantel de seda. En general la figura responde a la iconografía típica del Santo en los años cercanos a su canonización, siendo ésta la imagen más conocida y difundida del mismo, como lo demuestra, por ejemplo, la estampa realizada por Antonio Gómez para ilustrar el libro impreso por el Cabildo de la Catedral de Málaga con motivo de la fiesta que realizara el 31 de mayo de 1671 para conmemorar su llegada a los altares ${ }^{18}$.

${ }_{18}$ Véase la misma estudiada en El esplendor de la memoria. El arte de la Iglesia de Málaga. Catálogo de la exposición, 1998, p. 190. 
Como indicó Moreno Cuadro respeto a las fiestas sevillanas de 1671, esta iconografía muestra al Santo como al Monarca Universal, en base al prototipo establecido por Dante en su Monarquía, ya que Fernando III inauguró la Paz Cristiana, uno de los temas más utilizados en las exaltaciones regias desde que con Carlos V comenzó a forjarse la idea de Imperio Universal que continuaría el Sacro Imperio Romano Germánico, en un momento en que la desintegración del Imperio español era un hecho constatado ${ }^{19}$.

Fecha de recepción: 28-I-2008

Fecha de aceptación: 9-VI-2008

19 Moreno Cundro, F., 1989, pp. 37-38.

AEA, LXXXII, 325, ENERO-MARZO 2009, 35-46, ISSN: 0004-0428 